\title{
Metabolic Consequences of Oral Administration of 24,25-Dihydroxycholecalciferol to Uremic Dogs
}

\author{
Janet M. Canterbury, George Gavellas, Jacques J. Bourgoignie, and \\ ERIC REISs, Department of Medicine, and Laboratory of the Howard Hughes \\ Medical Institute, University of Miami School of Medicine, Miami, Florida 33101
}

A B S T R A C T 24,25-dihydroxycholecalciferol [24,25$(\mathrm{OH})_{2} \mathrm{D}_{3}$ ], once considered a relatively inert metabolite of vitamin $D_{3}$, has been recently recognized as a metabolically active product in some species. In previous studies, we have shown that infusion of $24,25(\mathrm{OH})_{2} \mathrm{D}_{3}$ into the thyroid artery of normal dogs results in prompt and complete suppression of parathyroid hormone (PTH) secretion. In this study, we have examined the metabolic consequences of oral administration of this metabolite in dogs with experimentally induced renal hyperparathyroidism. Dogs with comparable degrees of renal insufficiency (glomerular filtration rate, 10-15 $\mathrm{ml} / \mathrm{min}$ ) were treated for $3 \mathrm{wk}$ with daily doses of either $2 \mu \mathrm{g}$ of $24,25(\mathrm{OH})_{2} \mathrm{D}_{3}$ or $50 \%$ ethanol, the vehicle in which the metabolite was suspended. After a 6-wk recovery period, treatments were reversed: dogs who had previously served as controls received the metabolite while dogs previously treated with metabolite received the vehicle. Administration of $24,25(\mathrm{OH})_{2} \mathrm{D}_{3}$ resulted in a $40-60 \%$ decrease of immunoreactive PTH. This was associated with a small $(0.1-0.2 \mathrm{mg} / \mathrm{dl})$ but unequivocal decrease of serum ionized calcium. Calcium balance, which was slightly negative under control conditions, became slightly but definitively positive on treatment with $24,25(\mathrm{OH})_{2} \mathrm{D}_{3}$. All other parameters measured, including total serum calcium, magnesium, phosphorus, creatinine, electrolytes, phosphorus excretion, and phosphorus balance, remained unchanged. The data support the hypothesis that $24,25(\mathrm{OH})_{2} \mathrm{D}_{3}$ not only decreases PTH secretion but also functions as an anabolic hormone in bone under the conditions of this experiment.

\section{INTRODUCTION}

In recent years, the essential outlines of the metabolism of vitamin $\mathrm{D}$ have been elucidated $(1,2)$. Special

This work was presented in part at the Fourth Workshop on Vitamin D, Berlin, West Germany, February 1979.

Received for publication 25 May 1979 and in revised form 12 October 1979. attention has been focused on the regulation of the renal enzyme $1 \alpha$-hydroxylase, which converts 25 -hydroxycholecalciferol $\left[25(\mathrm{OH}) \mathrm{D}_{3}\right]^{1}$ to 1,25-dihydroxycholecalciferol $\left[1,25(\mathrm{OH})_{2} \mathrm{D}_{3}\right]$ in the kidney, because $1,25(\mathrm{OH})_{2} \mathrm{D}_{3}$ is generally considered the most active and therapeutically promising metabolite of vitamin $\mathrm{D}$. When $24,25-$ dihydroxycholecalciferol $\left[24,25(\mathrm{OH})_{2} \mathrm{D}_{3}\right]$ was first discovered, it was assumed to be a physiologically unimportant metabolite since, in equimolar ratios, its potency in increasing intestinal calcium absorption and bone resorption was considerably less than that of $1,25(\mathrm{OH})_{2} \mathrm{D}_{3}$.

Russell et al. (3) have extensively reviewed some physiologic and pharmacologic aspects of $24,25(\mathrm{OH})_{2} \mathrm{D}_{3}$. Their studies show that, in contrast to earlier studies, $1,25(\mathrm{OH})_{2} \mathrm{D}_{3}$ and $24,25(\mathrm{OH})_{2} \mathrm{D}_{3}$ are equivalently effective in increasing intestinal calcium absorption in healthy subjects as well as in patients with chronic renal failure. Gueris et al. (4) compared the effects of these two dihydroxylated metabolites in adults with nutritional osteomalacia. Both decreased serum immunoreactive parathyroid hormone (iPTH), but in the $1,25(\mathrm{OH})_{2} \mathrm{D}_{3}$-treated group the serum calcium increased significantly while, in the $24,25(\mathrm{OH})_{2} \mathrm{D}_{3}$-treated group, serum calcium remained low. In normal man, Brickman et al. (5) reported that $24,25(\mathrm{OH})_{2} \mathrm{D}_{3}$ increased intestinal calcium absorption in the presence of a slight fall in serum calcium. Llach et al. (6) noted that, in uremic man, $24,25(\mathrm{OH})_{2} \mathrm{D}_{3}$ significantly decreased the serum calcium and increased the serum alkaline phosphatase.

Our studies have been focused on the effects of vitamin D metabolites on PTH secretion in the dog $(7,8)$ and this report represents an extension of previous investigations. Care et al. (9) who pioneered the development of animal models for the study of PTH secretion, first reported evidence suggesting a suppressive effect of $24,25(\mathrm{OH})_{2} \mathrm{D}_{3}$ on PTH secretion. Our

\footnotetext{
${ }^{1}$ Abbreviations used in this paper: 25-hydroxycholecalciferol, $25(\mathrm{OH}) \mathrm{D}_{3} ; 1,25$-dihydroxycholecalciferol, $1,25(\mathrm{OH})_{2} \mathrm{D}_{3} ; 24,25$ dihydroxycholecalciferol, $24,25(\mathrm{OH})_{2} \mathrm{D}_{3}$; immunoreactive parathyroid hormone, iPTH; parathyroid hormone, PTH.
} 
studies confirmed and greatly extended these observations in normal and uremic dogs. The physiologic and potentially therapeutic implications of these studies could not be assessed because the model used did not permit determination of the concentration of 24,25$(\mathrm{OH})_{2} \mathrm{D}_{3}$ perfusing the parathyroid glands. In our model, the metabolite was infused directly into the thyroid artery and its volume of distribution was unknown. However, regardless of the assumptions that could be made about the volume of distribution, the doses used were clearly high (7).

In this study, we document in detail the metabolic consequences of the oral administration of $24,25(\mathrm{OH})_{2} \mathrm{D}_{3}$ to uremic dogs. This metabolite slightly decreased the serum ionized calcium concentration, reversed negative calcium balance, and profoundly suppressed serum iPTH concentrations.

\section{METHODS}

Experimental design. Five healthy adult female mongrel dogs weighing 13-20 kg were studied. Renal insufficiency was induced by ligation of the majority of the branches of the renal artery on one side followed, 2 wk later, by contralateral nephrectomy. This model has been described in detail elsewhere (10). After a period of stabilization varying from 1 to 3 mo, the dogs were studied according to the following protocol: $7 \mathrm{~d}$ before the start of each study, the dogs were placed in metabolic cages to adjust them to the conditions of the study. Each study sequence consisted of $1 \mathrm{wk}$ of control observations followed by 3 wk during which the animals received either ethanol, the vehicle in which $24,25(\mathrm{OH})_{2} \mathrm{D}_{3}$ was suspended, or $24,25(\mathrm{OH})_{2} \mathrm{D}_{3}$. Two experiments were performed on four dogs simultaneously. In the first experiment, two of the dogs received ethanol and two received $24,25(\mathrm{OH})_{2} \mathrm{D}_{3}$. After a 6-wk recovery period on completion of the first experiment, the treatments were reversed so that dogs who had previously received ethanol were given $24,25(\mathrm{OH})_{2} \mathrm{D}_{3}$ and vice versa. The complete design could not be executed because one of the dogs became ill during the 6-wk recovery phase and another dog had to be substituted. To preserve the efficiency of the design, statistical analysis of results was restricted to the three dogs in which the original design could be completely maintained. In the second experiment, treatments and observations were extended for 4 additional wk. Though excluded from the statistical analysis, the data obtained in the unpaired dogs are presented in Figs. 1 and 2.

The dogs were given Purina high protein dog meal containing $1.6 \mathrm{~g}$ calcium, $0.95 \mathrm{~g}$ phosphorus, and $176 \mathrm{U}$ of vitamin $\mathrm{D} / \mathbf{1 0 0} \mathrm{g}$ of diet (Ralston Purina Co., St. Louis, Mo.). Analysis of the diet confirmed the labeled value for the diet's calcium and phosphorus concentration within $10 \% .300 \mathrm{~g}$ of the diet was offered daily at the same time. The amount of diet actually taken by the dogs was determined by the difference of food available to the dogs and the amount remaining at the end of each day. One dog consistently ate all the food offered. The dogs were allowed access to distilled water in ad lib. amounts.

$50 \%$ ethanol or $2 \mu \mathrm{g}$ of $24,25(\mathrm{OH})_{2} \mathrm{D}_{3}$ suspended in $50 \%$ ethanol were given in a total volume of $3 \mathrm{ml}$ daily via a small catheter directly into the oral pharynx. $24,25(\mathrm{OH})_{2} \mathrm{D}_{3}$, a gift of Dr. H. Henry and Dr. A. W. Norman, Department of Biochemistry, University of California, Riverside, Calif., was chemically synthesized and drystalline. Upon analysis, it ex-

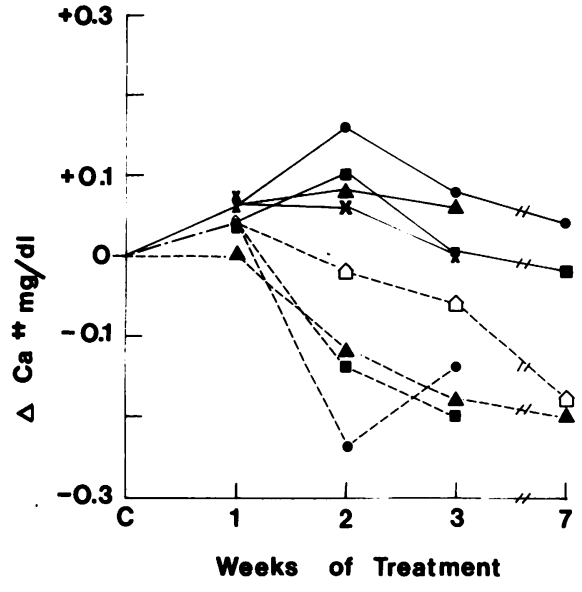

FIGURE 1 Ionized calcium concentrations in vehicle-treated $(-)$ and in $24,25(\mathrm{OH})_{2} \mathrm{D}_{3}$-treated dogs (-----). Identification of individual dogs is as follows: $\mathrm{LO}(\mathbf{O})$; $\mathrm{SC}(\mathbf{\Delta})$; TA ( $\boldsymbol{\square})$ (paired observations on these three dogs); LB $(\triangle)$; and LN $(\times)$ (nonpaired dogs). Each point represents the mean of three individual samples obtained during that period of study. The data are plotted as change of absolute concentration from the control period.

hibited a typical ultraviolet spectrum at $264 \mathrm{nM}$ for vitamin D compounds, and yielded a single component on Sephadex LH-20 (Pharmacia Fine Chemicals, Pharmacia, Inc., Piscataway, N. J.) and on high-pressure liquid chromatography. The metabolite was stored in absolute ethanol and diluted just before its administration.

Blood samples were obtained anaerobically, without stasis, three times a week. They were obtained at 10 a.m. from an anterior limb vein before changing the animals' food. Samples were analyzed for sodium, potassium, phosphorus, magnesium, total calcium, ionized calcium, iPTH, and creatinine. $10 \mathrm{ml}$ of serum were frozen and saved for future vitamin D metabolite analysis. Complete blood counts were performed once a week.

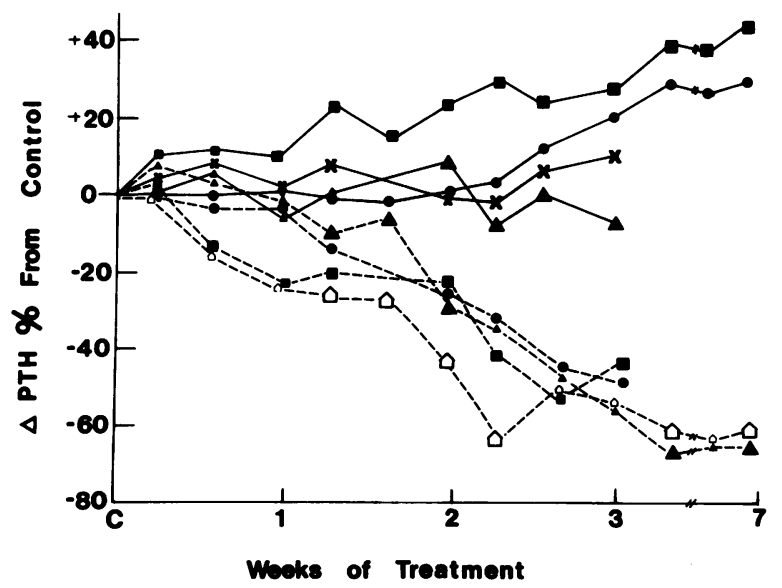

FIGURE 2 Serum iPTH as percentage of the control. Identification of dogs and treatments is the same as in Fig. 1. Each point represents the mean of determinations performed on a single sample drawn during the study. 
Methods. Formal $72 \mathrm{~h}$ metabolic balance were performed during every week of study. In the first experiment, urines were collected every $24 \mathrm{~h}$. In the second experiment, $24 \mathrm{~h}$ urine collections were obtained only when formal balance measurements were underway. Urines were collected in the cold in $10 \mathrm{ml}$ of glacial acetic acid and aliquots were analyzed for calcium, phosphorus, and creatinine. Carmine red was given via an orogastric tube on Mondays and Thursdays (11) and all stool passed between the appearance of the markers was collected. Stools were weighed, homogenized in distilled water, and brought to a weight of $2,000 \mathrm{~g}$. With the blender operating, two $50-\mathrm{g}$ aliquots were removed, dried at $100^{\circ} \mathrm{C}$ for $24 \mathrm{~h}$, and ashed at $600^{\circ} \mathrm{C}$ for $16 \mathrm{~h}$. The ash was taken up in $6 \mathrm{~N}$ hydrochloric acid, brought to volume, and analyzed for calcium and phosphorus $(11,12)$. Sodium and potassium were measured in blood and urine by flame photometry (Instrumentation Laboratories, Inc., Lexington, Mass.; model 143). Total calcium and magnesium were measured in all specimens by atomic absorption (Perkin-Elmer Corp., Instrument Div., Norwalk, Conn.; model 107). Phosphorus and creatinine were measured by modified AutoAnalyzer methods (AutoAnalyzer II; Technicon Instruments Corp., Tarrytown, N. Y.). Ionized calcium was measured by use of a selective ion flowthrough electrode (Orion Research Inc., Cambridge, Mass.; model SS20). Measurements were made in quadruplicates. Serum iPTH was assayed by methods previously described in great detail $(7,13-15)$. The antiserum used cross-reacted with intact hormone as well as $\mathrm{NH}_{2}$ - and $\mathrm{COOH}$-terminal fragments. Each sample was assayed in triplicate at two widely differing concentrations. To eliminate interassay variations, all samples for serum iPTH from a single experiment were frozen at $-20^{\circ} \mathrm{C}$ until immunoassayed on a single day.

Statistical analysis. The data were analyzed by analysis of variance, multiple classification (16). The treatments given, dogs, and weeks of study were treated as main effects. The triple interaction of these effects was used in assessing the significance of the interaction between treatments and weeks. When another error term was appropriate it is so indicated in the text. The design of the experiment and this form of analysis proved highly sensitive for detecting small reproducible changes, since the large variation between dogs was effectively eliminated from experimental error.

\section{RESULTS}

The dogs had stable renal insufficiency with a glomerular filtration rate of $10-15 \mathrm{ml} / \mathrm{min}$. The fractional excretion of phosphate ranged between 32 and $53 \%$ and iPTH was markedly increased, appropriate to the degree of renal failure.

Serum ionized calcium. The data are presented in Fig. 1 and Table I. For each period, the mean of three separate samples is given. Treatment with $24,25(\mathrm{OH})_{2} \mathrm{D}_{3}$ resulted in a small but highly significant decrease of ionized calcium compared to the vehicle $(P<0.001)$. This decrease of ionized calcium concentration became evident only during the $2 \mathrm{nd}$ wk. In contrast to these changes of ionized calcium, no significant changes in total calcium could be detected. Although the statistical analysis was restricted to the three dogs in whom complete paired data were available, all of the data are presented in Fig. 1. In two control dogs and two 24,25$(\mathrm{OH})_{2} \mathrm{D}_{3}$-treated dogs, the treatments were continued for an additional $4 \mathrm{wk}$. This marked prolongation of the treatment period decreased the ionized calcium by only a very small additional amount in the $24,25(\mathrm{OH})_{2} \mathrm{D}_{3}$ treated dogs.

iPTH. The data are presented in Fig. 2 and Table I. Results are given in absolute values in Table $I$ and as the percentage of control in Fig. 2. iPTH decreased progressively in the $24,25(\mathrm{OH})_{2}$ D3-treated dogs and remained constant or increased slightly in the vehicletreated dogs $(P<0.001)$. In two of the vehicle-treated dogs (SC and LN), iPTH remained constant, while in the two others (LO and TA) iPTH increased substantially. A possible explanation of this difference is that the latter dogs had earlier received $24,25(\mathrm{OH})_{2} \mathrm{D}_{3}$ and, 6 wk later at the initiation of the second study, control iPTH values had not yet returned to the previous base-line levels. It may be that in these dogs, the rise in iPTH represents a return to a iPTH concentration appropriate for the degree of renal insufficiency. This suggestion is supported by the data in Table I.

Calcium balance. The data are presented for one $\operatorname{dog}(\mathrm{LO})$ in Fig. 3 and for all animals in Table I. This is the only animal who maintained constant food intake throughout the entire study. Qualitatively similar results were obtained in the other dogs. On treatment with vehicle alone, all dogs were in slightly negative calcium balance. Calcium balance became slightly positive on treatment with $24,25(\mathrm{OH})_{2} \mathrm{D}_{3}$. The treatment effect was statistically significant for all $\operatorname{dogs}(P<0.03)$. For this comparison, the error term used was the treatment-dog interaction. On treatment with $24,25(\mathrm{OH})_{2} \mathrm{D}_{3}$, fecal calcium decreased $(P<0.04)$ as did the ratio of fecal calcium:calcium intake $(\mathrm{P}<0.025$, error term, treatment-dog interaction). Urine calcium decreased slightly but not significantly.

Other variables. No significant changes were recorded for the following variables: serum sodium; potassium; total calcium, magnesium, and creatinine; fecal phosphorus; weight of the dogs; and hemogram. No significant changes occurred in the following derived data: creatinine clearance, fractional excretion of sodium, fractional excretion of phosphate, and phosphorus balance.

\section{DISCUSSION}

The design of this study was highly efficient in documenting statistical significance of small changes in only three dogs. With a less efficient design, the effect of $24,25(\mathrm{OH})_{2} \mathrm{D}_{3}$ in decreasing ionized calcium concentration could not have been documented convincingly. Very large changes such as those occurring in serum iPTH, of course, do not require such a refined design. Although the formal statistical analysis was limited to data derived from animals in whom the complete design could be maintained, the data shown in the figures clearly indicate that the basic trend was the same in nonpaired animals. 
TABLE I

Metabolic Balances in Dogs Receiving Vehicle or $24,25(\mathrm{OH})_{2} D_{3}$

\begin{tabular}{|c|c|c|c|c|c|c|c|c|c|c|c|c|c|}
\hline \multirow{2}{*}{$\begin{array}{l}\text { Animal and } \\
\text { treatment* }\end{array}$} & \multirow[b]{2}{*}{ Week } & \multirow[b]{2}{*}{$\mathrm{Ca}^{++}$} & \multirow{2}{*}{$\begin{array}{c}\text { Serum } \\
\text { phosphorus }\end{array}$} & \multirow[b]{2}{*}{ iPTH $\ddagger$} & \multirow[b]{2}{*}{$\mathrm{C}_{\mathrm{CR}}$} & \multicolumn{4}{|c|}{ Calcium } & \multicolumn{4}{|c|}{ Phosphorus } \\
\hline & & & & & & Intake & Urine & Feces & Balance & Intake & Urine & Feces & Balance \\
\hline & & $m g / d l$ & $m g / d l$ & ul eq/ml & & \multicolumn{4}{|c|}{$\mathrm{g} / 72 \mathrm{~h}$} & \multicolumn{4}{|c|}{$\mathrm{g} / 72 \mathrm{~h}$} \\
\hline SC & Control & 5.20 & 5.4 & 740 & 6.23 & 14.40 & 0.069 & 15.30 & -0.98 & 8.55 & 0.995 & 7.47 & -0.07 \\
\hline \multirow[t]{3}{*}{ Vehicle } & 1 & 5.26 & 5.3 & 745 & 6.80 & 13.65 & 0.098 & 13.76 & -0.21 & 8.10 & 1.130 & 7.36 & -0.39 \\
\hline & 2 & 5.28 & 5.7 & 745 & 6.83 & 14.40 & 0.087 & 14.80 & -0.49 & 8.55 & 0.989 & 7.60 & -0.03 \\
\hline & 3 & 5.26 & 6.1 & 750 & 6.60 & 10.49 & 0.094 & 10.49 & -0.94 & 6.23 & 1.160 & 4.86 & +0.21 \\
\hline \multirow[t]{4}{*}{$24,25(\mathrm{OH})_{2} \mathrm{D}_{3}$} & Control & 5.38 & 5.5 & 730 & 7.83 & 14.40 & 0.081 & 16.28 & -1.96 & 8.55 & 1.200 & 8.27 & -0.92 \\
\hline & 1 & 5.38 & 6.4 & 570 & 7.73 & 14.40 & 0.070 & 14.20 & +0.13 & 8.55 & 1.570 & 8.24 & -1.26 \\
\hline & 2 & 5.26 & 6.6 & 400 & 7.43 & 11.28 & 0.057 & 10.88 & +0.40 & 8.55 & 1.380 & 6.21 & -0.89 \\
\hline & 3 & 5.20 & 6.3 & 340 & 7.63 & 14.40 & 0.098 & 12.20 & +2.11 & 8.55 & 1.350 & 7.68 & -0.48 \\
\hline LO & Control & 5.42 & 6.5 & 705 & 11.66 & 14.40 & 0.180 & 15.20 & -0.98 & 8.55 & 1.700 & 7.12 & -0.27 \\
\hline \multirow[t]{3}{*}{ Vehicle } & 1 & 5.48 & 6.6 & 690 & 11.31 & 14.40 & 0.170 & 15.60 & -1.37 & 8.55 & 1.970 & 8.32 & -1.74 \\
\hline & 2 & 5.56 & 6.5 & 705 & 11.47 & 14.40 & 0.190 & 14.60 & -0.43 & 8.55 & 1.940 & 7.84 & -1.23 \\
\hline & 3 & 5.50 & 6.6 & 830 & 11.80 & 14.40 & 0.180 & 14.72 & -0.50 & 8.55 & 1.860 & 9.04 & -2.35 \\
\hline \multirow[t]{4}{*}{$24,25(\mathrm{OH})_{2} \mathrm{D}_{3}$} & Control & 5.46 & 5.6 & 825 & 11.90 & 14.40 & 0.230 & 14.43 & -0.26 & 8.55 & 1.740 & 6.76 & +0.05 \\
\hline & 1 & 5.50 & 5.3 & 675 & 12.40 & 14.40 & 0.240 & 13.92 & +0.24 & 8.55 & 1.870 & 6.64 & +0.04 \\
\hline & 2 & 5.22 & 5.4 & 510 & 10.03 & 14.40 & 0.147 & 12.80 & +1.45 & 8.55 & 1.460 & 6.24 & +0.85 \\
\hline & 3 & 5.32 & 5.2 & 410 & 12.71 & 14.40 & 0.180 & 13.36 & +0.86 & 8.55 & 1.860 & 6.96 & -0.27 \\
\hline TA & Control & 5.50 & 4.4 & 465 & 14.73 & 14.40 & 0.250 & 14.97 & -0.82 & 8.55 & 1.330 & 8.00 & -0.78 \\
\hline \multirow[t]{3}{*}{ Vehicle } & 1 & 5.54 & 4.7 & 525 & 14.47 & 14.40 & 0.105 & 15.37 & -1.08 & 8.55 & 1.490 & 7.14 & -0.08 \\
\hline & 2 & 5.60 & 4.6 & 555 & 13.92 & 11.97 & 0.070 & 11.88 & +0.02 & 7.11 & 1.290 & 5.94 & -0.12 \\
\hline & 3 & 5.50 & 4.2 & 575 & 14.70 & 14.40 & 0.089 & 14.50 & -0.19 & 8.55 & 1.620 & 7.20 & -0.27 \\
\hline \multirow[t]{4}{*}{$24,25(\mathrm{OH})_{2} \mathrm{D}_{3}$} & Control & 5.54 & 4.5 & 560 & 13.51 & 14.40 & 0.150 & 14.56 & -0.31 & 8.55 & 1.210 & 6.40 & +0.94 \\
\hline & 1 & 5.58 & 4.6 & 480 & 13.70 & 14.40 & 0.120 & 13.77 & +0.50 & 8.55 & 0.950 & 7.79 & -1.90 \\
\hline & 2 & 5.40 & 4.2 & 335 & 14.32 & 11.07 & 0.140 & 10.64 & +0.29 & 6.57 & 1.130 & 6.24 & -0.80 \\
\hline & 3 & 5.34 & 4.1 & 270 & 15.01 & 13.90 & 0.130 & 12.96 & +0.81 & 8.27 & 1.450 & 7.20 & -0.38 \\
\hline LN & Control & 4.96 & 4.5 & 560 & 8.82 & 3.42 & 0.036 & 3.83 & -0.45 & 2.03 & 0.560 & 1.98 & -0.51 \\
\hline \multirow[t]{3}{*}{ Vehicle } & 1 & 5.04 & 4.2 & 545 & 8.91 & 5.60 & 0.060 & 5.72 & -0.18 & 3.35 & 0.480 & 3.48 & -0.61 \\
\hline & 2 & 5.04 & 4.0 & 555 & 11.63 & 9.79 & 0.090 & 10.10 & -0.40 & 5.81 & 0.690 & 5.41 & -0.32 \\
\hline & 3 & 5.00 & 4.2 & 590 & 13.74 & 9.49 & 0.090 & 8.04 & -1.36 & 5.63 & 0.610 & 4.38 & +0.64 \\
\hline LB & Control & 5.52 & 3.5 & 285 & 16.41 & 14.40 & 0.076 & 14.36 & -0.03 & 8.55 & 1.030 & 7.90 & -0.38 \\
\hline \multirow[t]{3}{*}{$24,25(\mathrm{OH})_{2} \mathrm{D}_{3}$} & 1 & 5.56 & 3.3 & 270 & 18.05 & 8.61 & 0.076 & 6.68 & +1.85 & 5.11 & 1.210 & 3.68 & +0.21 \\
\hline & 2 & 5.50 & 3.6 & 215 & 15.87 & 6.65 & 0.029 & 4.92 & +1.70 & 3.95 & 0.680 & 2.38 & +0.39 \\
\hline & 3 & 5.40 & 3.7 & 135 & 17.49 & 11.79 & 0.072 & 9.72 & +1.99 & 7.00 & 1.230 & 6.08 & -0.31 \\
\hline
\end{tabular}

*Animal SC received vehicle first and then $25,25(\mathrm{OH})_{2} \mathrm{D}_{3}$. The sequence was reversed for dogs $\mathrm{LO}$ and TA.

† Canine normal range, 35-85.

Our observation of decreasing ionized calcium concentration on treatment with $24,25(\mathrm{OH})_{2} \mathrm{D}_{3}$ is in accord with the limited information available in the literature, mostly in abstract form. In none of the reported studies using oral administration of $24,25(\mathrm{OH})_{2} \mathrm{D}_{3}$ was ionized calcium measured. The reports of Brickman et al. (5) in normal man and of Llach et al. (6) in uremic man document a fall of total serum calcium on treatment with $24,25(\mathrm{OH})_{2} \mathrm{D}_{3}$. Gueris et al. (4) and Russell et al. (3) reported no change of the total calcium.

The pronounced suppression of serum iPTH observed in these studies confirms in intact animals what had previously been demonstrated by perfusion of the thyroid-parathyroid apparatus of dogs (7-9). The impressive feature of the suppression of iPTH in our experiments is that it occurred in the presence of a slightly decreasing ionized calcium concentration. By contrast, the suppression of iPTH that occurs with administra- tion of $1,25(\mathrm{OH})_{2} \mathrm{D}_{3}$ is regularly accompanied by a rise of serum calcium (17). Although our study documents dramatic and progressive suppression of serum iPTH, it is not possible to assess the degree of suppression of PTH secretion. The antiserum used in these studies is polyvalent and includes in its measurement $\mathrm{COOH}$ terminal fragments of PTH. These predominate in the circulation of animals with renal insufficiency. According to the studies of Freitag et al. (18) the half-life of these fragments in uremic animals is markedly prolonged; the half-life is on the order of days in uremic animals as compared to hours in normal animals. In the study of Silverman and Yalow (19), the half-life of $\mathrm{COOH}$-terminal fragments appeared to be of the order of weeks in an anephric man. On the basis of Freitag's data, one must assume that the suppression of iPTH observed in our experiments represents substantial but incomplete suppression of PTH secretion. That the 


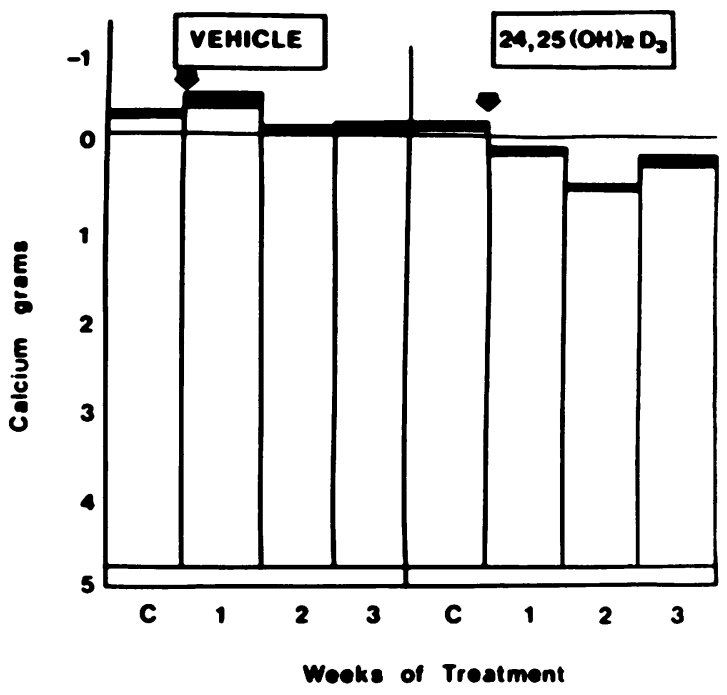

FIGURE 3 Calcium balance in dog LO. Intake is plotted from zero downward. The open area represents fecal calcium, the shaded area urinary calcium per $24 \mathrm{~h}$.

decrease of $\mathrm{PPTH}$ is a result of decreased PTH secretion rather that altered metabolism or clearance is evident from our previous studies. When $24,25(\mathrm{OH})_{2} \mathrm{D}_{3}$ was infused directly into the thyroid artery of a uremic dog, fractionation of the thyroid venous effluent serum showed disappearance of the intact hormone but persistence of fragments (8). In these studies, however, an additional effect on PTH metabolism can not be excluded.

Recently published data indicate that $24,25(\mathrm{OH})_{2} \mathrm{D}_{3}$ like $1,25(\mathrm{OH})_{2} \mathrm{D}_{3}$ increases calcium absorption from the intestines. In this study, calcium balance change significantly from slightly negative to slightly positive. An important feature of the results is that positive calcium balance was associated with a significant decrease of the ionized calcium concentration and a tendency toward lowering the urinary calcium. The most likely explanation of these changes is that calcium was deposited in bone. This interpretation is in conformance with the fragmentary data available in the literature (3-6). A comparison between the effect of $24,25(\mathrm{OH})_{2} \mathrm{D}_{3}$ and $1,25(\mathrm{OH})_{2} \mathrm{D}_{3}$ in intact animals is difficult because information concerning the former is incomplete. Both metabolites enhance calcium absorption from the intestines. With $1,25(\mathrm{OH})_{2} \mathrm{D}_{3}$, serum and urine calcium increase; with $24,25(\mathrm{OH})_{2} \mathrm{D}_{3}$ both decrease. A reasonable explanation for the difference of effects of these two metabolites is that $1,25(\mathrm{OH})_{2} \mathrm{D}_{3}$ possesses potent bone resorbing properties, whereas $24,25(\mathrm{OH})_{2} \mathrm{D}_{3}$ does not. It is tempting to speculate that $24,25(\mathrm{OH})_{2} \mathrm{D}_{3}$ is the form of the metabolite that principally promotes bone formation. It is also possible that the beneficial effects of $25(\mathrm{OH})_{2} \mathrm{D}_{3}$ in the treatment of renal osteodystrophy $(20,21)$ may be a result of further metabolism of $25(\mathrm{OH})_{2} \mathrm{D}_{3}$ to $24,25(\mathrm{OH})_{2} \mathrm{D}_{3}$.

Neither fractional excretion of phosphorus nor phosphorus balance changed on treatment with $24,25(\mathrm{OH})_{2} \mathrm{D}_{3}$. A possible explanation of these somewhat unexpected findings is that, despite marked suppression of PTH secretion, there remained a sufficiently high concentration of circulating PTH to provide maximal stimulation of the renal transport system for phosphate. Alternatively, $24,25(\mathrm{OH})_{2} \mathrm{D}_{3}$ may have a phosphaturic action, but his has not been demonstrated.

This study does not explore the long-term effects of $24,25(\mathrm{OH})_{2} \mathrm{D}_{3}$ on bone. Bone biopsies were not performed because one may not observe changes in bone histology in such a short-term study. Besides, we did not wish to risk injury to the dogs.

The study also leaves open the question of optimal dosage and blood levels of $24,25(\mathrm{OH})_{2} \mathrm{D}_{3}$ required to obtain the recorded effects. The dosage was probably high for a dog. In most human studies, positive effects on gastrointestinal calcium absorption have been obtained with $1-5 \mu \mathrm{g}$ of $24,25(\mathrm{OH})_{2} \mathrm{D}_{3} / \mathrm{d}$. The methodology for the measurement of $24,25(\mathrm{OH})_{2} \mathrm{D}_{3}$ in serum is still too uncertain for attempting this measurement in our laboratory. We have available abundant quantities of serum for future analysis. It is probable that the plasma levels of $24,25(\mathrm{OH})_{2} \mathrm{D}_{3}$ required for changes in ionized calcium and iPTH were high. Ionized calcium did not change during the lst wk of treatment nor did iPTH in two of four dogs. Since the half-life of $24,25(\mathrm{OH})_{2} \mathrm{D}_{3}$ is long, on the order of $15-40 \mathrm{~d}(3)$, the cumulative effect of repeated doses was presumably required before a convincing metabolic effect became evident.

These studies support our previous suggestion that $24,25(\mathrm{OH})_{2} \mathrm{D}_{3}$ may have important therapeutic uses. The metabolite appears to deserve a systematic therapeutic trial in uremic osteodystrophy.

\section{ACKNOWLEDGMENTS}

We are indebted to Dr. Helen Henry and Dr. Anthony W. Normany for supplying us with the $24,25(\mathrm{OH})_{2} \mathrm{D}_{3}$ used in this study.

This work was supported by grants AM-16768 and AM19822 from the National Institutes of Health.

\section{REFERENCES}

1. Haussler, M. R., and T. A. McCain. 1977. Basic and clinical concepts related to vitamin D metabolism and action. $N$. Engl. J. Med. 297: 974-983.

2. DeLuca, H. F., and H. K. Schnoes. 1976. Metabolism and mechanism of action of vitamin D. Annu. Rev. Biochem. 45: $631-666$.

3. Russell, R. G. G., J. A. Kanis, R. Smith, N. D. Adams, M. Bartlett, T. Cudy, M. Cochran, G. Heynen, and G. T. Warner. 1977. Physiological and pharmacological aspect of 24,25 dihydroxcholecalciferol in man. In Hemostasis of Phosphate and Other Minerals. Proceedings of the Third 
International Workshop on Phosphate and Other Mineral. Madrid, Spain, July 1977. Plenum Press, New York. 487-503.

4. Gueris, J. L., Ph. J. Bordier, H. Rassmussen, A. M. Gravlet, P. Marie, L. Miravet, and A. W. Norman. 1977. Control of secondary hyperparathyroidism by $1,25 \mathrm{DHCC}$ and 24,25 DHCC in adult nutritional osteomalacia. 6th Parathyroid Conference. Vancouver, Canada. 127. (Abstr.)

5. Brickman, A. S., K. Gerszi, A. W. Norman, and J. W. Coburn. 1978. 24,25 dihydroxy-vitamin $\mathrm{D}_{3}$. A sterol with unique effects in normal man. Clin. Res. 26: 411A. (Abstr.)

6. Llach, F., A. S. Brickman, K. Gerszi, A. W. Norman and J. W. Coburn. 1978. Actions of 24,25 dihydroxy-vitamin $\mathrm{D}_{3}$ in uremic man. Clin. Res. 26: 543A. (Abstr.)

7. Canterbury, J. M., S. Lerman, A. L. Claflin, H. Henry, A. Norman, and E. Reiss. 1978. Inhibition of parathyroid hormone secretion by 25-hydroxycholecalciferol and 24,25 dihydroxycholecalciferol in the dog. J. Clin. Invest. 61: 1375-1383.

8. Canterbury, J. M., G. Gavellas, J. Bourgoignie, and E. Reiss. 1979. In vivo suppression of parathyroid hormone (PTH) secretion by 24,25 dihydroxy cholecalciferol $\left(24,25(\mathrm{OH})_{2} \mathrm{D}_{3}\right)$ in hyperparathyroid dogs. In Vitamin D Basic Research and its Clinical Application. A. W. Norman, K. Schaefer, D. V. Herrath, H-G. Grigdeit, J. W. Coburn, H. F. DeLuca, E. B. Mawer, and T. Suda, editors. Walter de Gruyter \& Co., Berlin. 297-304.

9. Care, A. D., R. F. L. Bates, D. W. Pickard, M. Peakcok, S. Tomlinson, J. L. H. Riordan, E. B. Mawer, C. M. Taylor, H. F. DeLuca, and A. W. Norman. 1977. The effects of vitamin $\mathrm{D}$ metabolites and their analogues on the secretion of parathyroid hormone. Calcif. Tissue Res. 21: $142-146$.

10. Schultz, R., H. Shapiro, and N. S. Bricker. 1969. Studies on the control of sodium excretion in experimental uremia. J. Clin. Invest. 48: 869-877.

11. Reifenstein, E. C., Jr., F. Albright, and S. L. Wells. 1945. the accumulation interpretation and presentation of data pertaining to metabolic balances, notably those of calcium, phosphorus, and nitrogen. J. Clin. Endocrinol. Metab. 5: 367-395.

12. Figueroa, W. G., T. Jordan, and S. Basseh. 1968. Use of barium sulfate as an unabsorable fecal marker. Am. J. Clin. Nutr. 1239-1245.

13. Canterbury, J. M., and E. Reiss. 1972. Multiple immunoreactive molecular forms of parathyroid hormone in human serum. Proc. Soc. Exp. Biol. Med. 140: 1393-1398.

14. Canterbury, J. M., G. S. Levey, and E. Reiss. 1973. Activation of renal cortical adenylate cyclase by circulating immunoreactive parathyroid hormone: in human serum. J. Clin. Invest. 52: 524-527.

15. Canterbury, J. M., L. A. Bricker, G. S. Levey, P. L. Kozlovskis, E. Ruiz, J. E. Zull, and E. Reiss. 1975. Metabolism of bovine parathyroid hormone: immunological and biological characteristics of fragments generated by the liver perfusion. J. Clin. Invest. 55: 1245-1253.

16. Mather, K. 1947. Statistical Analysis in Biology. Interscience Publishers, Inc. New York. 61.

17. Brickman, A. W., J. W. Boburn, and A. W. Norman. 1972. Action of 1,25-dihydroxycholecalciferol, a potent kidneyproduced metabolite of vitamin $\mathrm{D}_{3}$ in uremic man. $N$. Engl. J. Med. 287: 891-895.

18. Freitag, J., K. J. Martin, K. A. Hruska, C. Anderson, M. Conrades, J. Ladenson, S. Klahr, and E. Slatopolsky. 1978. Impaired parathyroid hormone metabolism in patients with chronic renal failure. N. Engl. J. Med. 298: 29-55.

19. Silverman, R., and R. S. Yallow. 1972. Heterogeneity of parathyroid hormone: clinical and physiologic implications. J. Clin. Invest. 52: 1958-1971.

20. Bordier, P., A. Ryckwaert, P. Marie, L. Miravet, A. Norman, and H. Rasmussen. 1977. Vitamin D. metabolites and bone mineralization in man. In Vitamin D Biochemical, and Chemical and Clinical Aspects Related to Calcium Metabolism. Proceedings of Third Workshop on Vitamin D. Norman, A. W., K. Schraefer, J. W. Colum, H. F. DeLuca, D. Fraser, H. G. Grigoleit, and D. V. Herrath, editors. January 1977. Walter de Gruyter \& Co., Berlin. 897-911.

21. Rutherford, W. E., P. Bordier, P. Marie, K. Hruska, H. Harter, A. Greenwalt, J. Blondin, J. Haddad, N. S. Bricker, and E. Slatopolsky. 1977. Phosphate control and 25hydroxycholecalciferol administration in preventing experimental renal osteodystrophy in the dog. J. Clin. Invest. 60: 332-341. 